\title{
Current State of Respiratory Syncytial Virus Disease and Management
}

\author{
Archana Chatterjee $\cdot$ Kunjana Mavunda $\cdot$ Leonard R. Krilov
}

Received: December 8, 2020 / Accepted: December 9, 2020 / Published online: March 3, 2021

(C) The Author(s) 2021

\section{ABSTRACT}

Respiratory syncytial virus (RSV) is a major cause of hospitalizations due to pneumonia and bronchiolitis. Substantial morbidity and socioeconomic burden are associated with RSV infection worldwide. Populations with higher susceptibility to developing severe RSV include premature infants, children with chronic lung disease of prematurity (CLDP) or congenital heart disease (CHD), elderly individuals aged $>65$ years, and immunocompromised individuals. In the pediatric population, RSV can lead to long-term sequelae such as wheezing and asthma, which are associated with increased health care costs and reduced quality of life. Treatment for RSV is mainly supportive, and general preventive measures such as good hygiene and isolation are highly recommended. Although vaccine development for RSV has

A. Chatterjee

Department of Pediatrics, Sanford Children's

Specialty Clinic, University of South Dakota Sanford

School of Medicine, Sioux Falls, SD, USA

K. Mavunda

Department of Pulmonary Medicine, Kidz Medical

Services, Coral Gables, FL, USA

L. R. Krilov $(\bowtie)$

Department of Pediatrics, NYU Langone Hospital-

Long Island, NYU Long Island School of Medicine,

Mineola, NY, USA

e-mail: Leonard.Krilov@nyulangone.org been a global priority, attempts to date have failed to yield a safe and effective product for clinical use. Currently, palivizumab is the only immunoprophylaxis (IP) available to prevent severe RSV in specific high-risk pediatric populations. Well-controlled, randomized clinical trials have established the efficacy of palivizumab in reducing RSV hospitalization (RSVH) in high-risk infants including moderate- to latepreterm infants. However, the American Academy of Pediatrics (AAP), in its 2014 policy, stopped recommending RSV IP use for $\geq 29$ weeks' gestational age infants. Revisions to the AAP policy for RSV IP have largely narrowed the proportion of pediatric patients eligible to receive RSV IP and have been associated with an increase in RSVH and morbidity. On the other hand, after reviewing the recent evidence on RSV burden, the National Perinatal Association, in its 2018 clinical practice guidelines, recommended RSV IP use for a wider pediatric population. As the AAP recommendations drive insurance reimbursements for RSV IP, they should be revised to help further mitigate RSV disease burden.

Keywords: American Academy of Pediatrics; Chronic lung disease; Congenital heart disease; High-risk preterm infants; Immunoprophylaxis; National Perinatal Association; Palivizumab; Respiratory syncytial 
virus; RSV hospitalization; Socioeconomic burden

\section{Key Summary Points}

Respiratory syncytial virus (RSV) is a global burden and a major cause of lower respiratory tract infections in young children.

Premature infants and immunocompromised or older adults (aged $\geq 65$ years) are at high risk of developing complications secondary to RSV infection.

RSV infection can present with nonspecific symptoms but more commonly as a lower respiratory tract infection (manifested as bronchiolitis and/or pneumonia), either of which can progress to cause respiratory failure.

There is no effective treatment or vaccine available for RSV; palivizumab is the only RSV immunoprophylaxis (IP) approved for use in specific high-risk pediatric populations.

Currently, the American Academy of Pediatrics (AAP) and the National Perinatal Association (NPA) have conflicting recommendations for palivizumab use in otherwise healthy 29-34 weeks' gestational age (wGA) infants.

Risk factor predictive models can be effective in identifying high-risk populations to promote cost-effective use of the only available RSV IP: palivizumab.

\section{DIGITAL FEATURES}

This article is published with digital features, including a summary slide, to facilitate understanding of the article. To view digital features for this article go to https://doi.org/10.6084/ m9.figshare.13326200.

\section{INTRODUCTION}

Respiratory syncytial virus (RSV) is a significant cause of respiratory illness worldwide in pediatric populations [1]. The virus was first isolated from chimpanzees with coryza in 1955 and later from infants and children during a bronchiolitis epidemic in the early 1960s [2, 3]. RSV belongs to the Pneumovirus family and Orthopneumovirus genus [4]. There are two antigenic subtypes, A and $\mathrm{B}$, with no significant correlation between the virus type and disease severity or plaque size [5]. The single-stranded RNA genome is enclosed in a lipoprotein envelope with major transmembrane proteins, including the glycoprotein $(\mathrm{G})$ and fusion protein (F). The G protein aids with viral attachment, and the F protein facilitates viral penetration and fusion with neighboring cells to form prominent syncytia [6]. Of note, the prefusion $F$ protein is a major immunogenic component and a target of several novel therapeutics in clinical development $[7,8]$. Both humoral and cytotoxic T-cellmediated immunity are vital for effective host defense against RSV. Natural infection does not provide lasting immunity against RSV infection; therefore, reinfections are common throughout life [9-11].

While there are animal RSV strains, humans are the only reservoir for human RSV infection. Transmission of the virus occurs commonly through direct or close exposure to infected secretions $[4,12]$. The virus can survive $6 \mathrm{~h}$ or longer on hard surfaces and $20 \mathrm{~min}$ on skin $[13,14]$. RSV infection is a seasonal illness with onset and offset, duration, and peak varying annually. The season further varies by geographic region; in the northern hemisphere, it usually lasts from November to April [4, 15]. The southern US, including Florida, has a longer RSV season, sometimes starting in July [16]. In tropical regions such as the US territory of Puerto Rico and equatorial regions such as the Philippines and Mozambique, the RSV season can last year-round with minimal seasonal variations $[17,18]$. This article will review the 
current disease state of RSV and discuss populations at high risk of developing severe RSV. In addition, guidance for prevention of RSV with immunoprophylaxis (IP) will be examined. This article is based on previously conducted studies and does not contain any studies with human participants or animals performed by any of the authors.

\section{EPIDEMIOLOGY AND BURDEN OF RSV}

RSV is a very common virus that infects almost every child before 2 years of age, and $>50 \%$ of those aged $<1$ year have been infected twice [11]. Because infection with RSV does not lead to long-term immunity, children and adults can have recurrent infections, although generally limited to the upper respiratory tract [8]. In the US, RSV has been a leading cause of hospitalization due to lower respiratory tract infections (LRTI) among infants aged $<1$ year [19]. In a population-based, active surveillance study, Jain et al. reported that RSV was the most common cause of pneumonia (28\%) in children aged $<5$ years, with the highest burden in children aged $<2$ years [20]. Hospitalization rates associated with RSV are about 16 times higher than those associated with influenza in infants aged $<1$ year [21]. In 2019, the Centers for Disease Control and Prevention (CDC) reported annual estimates of RSV-associated hospitalization (RSVH) and mortality among children aged $<5$ years were $>57,000$ and 100-500, respectively, and among elderly adults were 177,000 and 14,000, respectively [22]. Although diagnostic testing for RSV has increased in recent years, these are likely underestimates of RSV morbidity and mortality according to the CDC [22]. Moreover, the American Academy of Pediatrics (AAP) recommends against routine testing for RSV, which would further decrease identification of specific RSV infections [23]. Globally, the annual burden of RSVH and in-hospital mortality associated with acute LRTI were 3.2 million and 59,600 , respectively, among children aged $<5$ years and 336,000 and up to 50,500, respectively, in older adults $[24,25]$. The burden of RSV among the elderly is considered equivalent to that of non-pandemic influenza and has gained more recognition in recent years [25-27]. Although mortality due to RSV is less common in developed countries compared with developing countries, the societal and economic burden associated with RSVH is considerably high worldwide $[26,27]$.

\section{POPULATIONS AT INCREASED RISK FOR RSV INFECTION}

Specific subgroups of children and adults have a higher risk of developing severe RSV infection. Among infants and children, risk factors include prematurity, comorbidities such as chronic lung disease of prematurity (CLDP; formerly known as bronchopulmonary dysplasia [BPD]) or congenital heart disease (CHD), chromosomal abnormalities such as Down syndrome, immunodeficiency, and cystic fibrosis $[12,27]$. Children with congenital airway abnormalities (larynx, trachea, and bronchi), tracheostomy, and neuromuscular disease are also at higher risk of developing severe complications when infected with RSV [28, 29]. Adults who are immunosuppressed, receiving an organ transplant, or aged $\geq 65$ years are at increased risk of severe RSV disease [27].

A series of comprehensive, systematic reviews (REGAL [RSV Evidence-a Geographical Archive of the Literature]) of studies conducted between 1995 and 2015 in Western countries reported the risk of RSVH in pediatric high-risk populations: the RSVH rate in premature infants ranges between 5 and $>100$ per 1000 children, and premature infants have about a three times higher rate (range 1.1-8.1 times higher) of RSVH than full-term infants; the odds ratio of RSVH in children with CLDP ranges between 2.2 and 7.2 with the RSVH rate varying between 12 and 46\%; the RSVH rate in children with CHD ranges between 14 and 357 per 1000 [30-33]. Overall, data demonstrating the attributable risk of RSV in pediatric populations, including infants with Down syndrome, cystic fibrosis, and neuromuscular disease and those who are immunocompromised, are largely 
limited due to smaller numbers of such patients being available for well-designed studies [29].

\section{CLINICAL MANIFESTATIONS OF RSV}

In otherwise healthy older term infants (aged $>6$ weeks) and children, RSV usually affects only the upper respiratory tract and is self-limiting. Healthy and premature infants aged $<6$ weeks are at higher risk of complications, including apneic spells secondary to RSV infection. In general, infants with RSV may present with nonspecific signs and symptoms such as poor feeding, lethargy, tachypnea, irritability, and cyanosis. LRTI manifest as bronchiolitis and/or pneumonia and occur in $25-40 \%$ of children during their primary infection. Patients present with lower respiratory features such as cough, chest wall hyperexpansion, nasal flaring, intercostal retractions, hypoxemia, tachypnea, fever, wheezing, and inspiratory crackles. In severe cases, respiratory failure can occur and may require admission to the intensive care unit (ICU) and ventilatory support $[6,12,29,34]$. Clinical presentation in adults may range from mild cold-like upper respiratory tract symptoms to severe respiratory distress. Nonspecific clinical features such as loss of appetite, fever, and asthenia are common [26]. The weakening of the immune response in adults may increase their susceptibility to severe RSV disease [27]. The estimated risk of RSV associated with acute LRTI in adults aged $\geq 65$ years is 8.5 times higher than in healthy individuals [35].

\section{DETECTION AND MANAGEMENT OF RSV}

The three established methods used for the detection of RSV include polymerase chain reaction (PCR)-based RSV testing, antigen-based methods, and virus isolation in tissue culture. The CDC determines the RSV seasonality (onset, peak, duration, and offset) based on weekly data from participating laboratories across the US available through the National Respiratory and Enteric Virus Surveillance System (NREVSS). Although the CDC traditionally used antigen-based tests to describe the RSV season, the use of molecular testing with PCR is becoming more prevalent because of its increased sensitivity and accuracy. Detection of RSV is particularly challenging in elderly adults because of lower viral loads in their nasal secretions and shorter duration of viral shedding compared with children. PCR-based testing has improved detection of the lower levels of RSV in adults. In addition, antigen-based tests have higher detection thresholds and are less sensitive in detecting RSV infection among elderly adults compared with PCR-based assays [26]. For real-time detection of RSV, the CDC recommends the simple threshold method (3\% threshold for PCR and 10\% threshold for antigen detection test) [15].

Studies have shown that febrile, RSV-positive disease in infants and children may be associated with co-infections with other viral respiratory viruses such as rhinovirus, bocavirus, and adenovirus [36]. Despite the finding that infants and children with viral co-infections were more likely to have fever than those with single infections, associations with disease severity cannot be concluded [37]. RSV infections have also occurred in the setting of coexistence of pathogenic bacteria such as Moraxella; however, differentiating co-infections from colonization may be difficult. Co-infections with viral and bacterial pathogens may be associated with more severe respiratory disease [38, 39]. Although azithromycin treatment in infants hospitalized with RSV bronchiolitis was observed to prolong the time to a subsequent wheezing episode and led to a decrease in days with respiratory symptoms, treatment with antibiotics did not appear to benefit at the time of the infections [40]. These findings emphasize the need for prudent clinical examination of febrile RSV cases for such co-infections, which in turn is important for clinical decision-making and appropriate disease management.

Currently, the treatment of RSV is mainly supportive and includes supplemental oxygen, adequate hydration, and mechanical ventilatory support when needed. Ribavirin is the only licensed antiviral treatment for RSV; however, 
its use is limited to severe RSV infections in immunocompromised patients. This is because of its high cost, inconclusive efficacy overall, potential toxicity issues, and inconvenient route of administration [12, 13, 41]. Although initial studies reported a decrease in viral load, need for oxygen, and length of hospital stay, subsequent studies were unable to demonstrate consistent improvements in these clinical parameters among infants treated with ribavirin compared with placebo [13]. As aerosolized ribavirin has become very expensive in recent years (about $\$ 30,000 /$ day), oral ribavirin is being investigated for its cost-effectiveness and convenient route of administration in immunocompromised adults [42]. Beta-adrenergic drugs, corticosteroids, and hypertonic saline are often prescribed for children with acute bronchiolitis. They are largely ineffective and are not recommended routinely for use in severe RSV infection. Bacterial superinfection, other than possibly otitis media, is a rare complication of RSV infection. Hence, systemic antibiotics are not routinely indicated during RSV infection but may be prescribed when there is a high suspicion of bacterial superinfection $[12,23,26]$.

\section{PREVENTION OF RSV}

With limited treatment options available for $\mathrm{RSV}$, prevention is the most effective strategy to control RSV infection [43]. General measures recommended by the CDC and AAP to prevent RSV among high-risk infants include good hand hygiene among caregivers, limiting exposure to tobacco smoke, and avoiding overcrowded locations, including day care when possible [12]. As RSV is ubiquitous and highly contagious, droplet and contact isolation of infected patients, caregiver education on RSV transmission, and reinforcement of hygiene measures among health care professionals and families can help reduce nosocomial transmission of RSV $[12,14]$. Despite this, once RSV enters a day care or a home, almost everyone exposed will have some symptoms related to RSV infection. In the hospital setting, placing RSV-infected patients in single rooms or cohort areas is recommended in conjunction with droplet plus standard isolation precautions [12].

Initial attempts at active immunization for RSV began in the 1960s with the development of a formalin-inactivated vaccine, but this led to enhanced disease with natural RSV infection including several deaths. Subsequently, the safety standards for RSV vaccine development in young infants became more stringent. With improved understanding of the molecular biology of the virus and its immunologic determinants, a number of RSV vaccines are now in development, but it will be at least several years before they become available [41].

Palivizumab is currently the only approved IP for the prevention of RSV in specific high-risk infants [41]. RSV-IVIG (RespiGam), an enriched hyperimmune globulin, was approved in 1996 for $\leq 35$ wGA infants and children with BPD. Administration was time consuming (intravenous infusion over many hours), and the product was removed from the market following the approval of palivizumab [38, 44]. Palivizumab is a humanized, recombinant monoclonal antibody that binds and neutralizes RSV F protein. It is indicated to prevent severe LRTI caused by RSV in premature infants $(\leq 35$ wGA) aged $\leq 6$ months, children with BPD requiring medical treatment in the past 6 months and aged $\leq 24$ months, and children with hemodynamically significant CHD aged $\leq 24$ months. Palivizumab is available as 50-mg and 100-mg single-dose vials, and a total of up to five monthly intramuscular injections is recommended by the AAP at a dose of $15 \mathrm{mg}$ per kilogram of body weight, with the first dose ideally given before the start of the RSV season $[4,12]$. However, partial prophylaxis with fewer than the recommended five palivizumab doses is clinically common potentially because of patient out-of-pocket costs, insurance/payer restrictions, and physician preference, in addition to birth month during the RSV season. More than $65 \%$ of high-risk infants do not receive complete IP and are at a significantly higher risk of RSVH $(P<0.001)[45,46]$.

Two well-controlled, double-blind, randomized clinical trials established the safety and efficacy of palivizumab in high-risk infants and led to the FDA approval for the current 
indication [4]. In the Impact-RSV trial $(N=1502)$, administration of palivizumab vs. placebo resulted in a significant reduction of RSVH by $78 \%$ among $\leq 35$ wGA infants aged $<6$ months $(P<0.001)$ and by $39 \%$ in infants with BPD aged $\leq 24$ months $(P=0.038)$. Further subgroup analyses revealed significant benefit from prophylaxis in 32-35 wGA infants with or without BPD as well as those $<32$ wGA [47]. Feltes et al. assessed the efficacy of palivizumab in high-risk children with CHD aged $\leq 24$ months $(N=1287)$ during 1998-2002. Palivizumab administration resulted in a $45 \%$ reduction in RSVH $(P=0.003)$, $56 \%$ fewer days of RSVH $(P=0.003)$, and $73 \%$ fewer ICU admissions $(P=0.094)$ compared with placebo [48]. Both studies showed that palivizumab was well tolerated. Patients in the palivizumab group experienced adverse events similar to those in the placebo group with very few discontinuations [47, 48]. Currently, palivizumab is also approved for use in the European Union and in 45 other countries throughout the world [44].

Studies conducted after the approval of palivizumab have assessed its real-world effectiveness during the prophylaxis era. Farber et al. [49] evaluated nine Texas Medicaid databases from 2012 to 2014 and reported a significant decrease in RSVH rates among 29-32 wGA infants aged $\leq 6$ months who received $\geq 1$ doses of palivizumab (3.08\%) compared with those who did not receive RSV IP (4.97\%; $P=0.04)$. In an international, multicenter, prospective study, Anderson et al. estimated that the effectiveness of palivizumab in preventing RSVH among high-risk infants (including $<36$ wGA infants aged $\leq 1$ year and those with CHD or CLDP aged $<24$ months) was 58\%. Among 29-35 wGA infants aged $<6$ months without comorbidities, the effectiveness of palivizumab in preventing RSVH was estimated to be $74 \%$ [50]. Recent evidence has shown that palivizumab may have a potential role in reducing the incidence of RSVH and its severity in children with cystic fibrosis aged $<2$ years [51, 52]. However, further randomized controlled trials are necessary to examine the effectiveness of palivizumab in other high-risk groups beyond the current indication, including patients with cystic fibrosis.

\section{CHANGES IN RSV IP GUIDANCE}

Since the approval of palivizumab in 1998, the AAP Committee on Infectious Diseases has published recommendations every 5 years for RSV IP use in high-risk pediatric populations. The pediatric populations deemed high risk and eligible for RSV IP according to the AAP have differed from the FDA-approved indication of palivizumab (Table 1) [43, 44]. In the most recent policy published in 2014, and reaffirmed in 2019, the AAP further restricted use of RSV IP to include $<29$ wGA infants, children with BPD (all $<32$ wGA requiring $>21 \%$ oxygen for at least the first 28 days after birth, all aged $<12$ months at RSV season start, and all aged 12-24 months at RSV season start and requiring medications in the past 6 months), and children with CHD (all aged $<12$ months at RSV season start). For the first time, RSV IP was not recommended for otherwise healthy 29-35 wGA infants [53, 54]. Although some experts believe that cost was an influencing factor for the policy change, the AAP stated that the similar risk of RSVH in $>29$ wGA infants and term infants was the rationale for the change $[23,55]$. While the cost-effectiveness of palivizumab has been debated, many studies have shown that it is efficacious in the pediatric populations for which it is indicated [56]. Placebo-controlled randomized clinical studies have continually shown that palivizumab effectively reduces the risk of RSVH in 32-35 wGA infants. In the Impact-RSV trial, palivizumab reduced the risk of RSVH by $80 \%$ in $32-35$ wGA infants $(P=0.002)$ [47]. The MAKI trial reported a relative reduction of RSVH by $82 \%$ $(P=0.01)$ compared with placebo in $33-35$ wGA infants [57].

Following the 2014 AAP policy change, several real-world evidence studies assessed its impact on IP use and RSVH in 29-34 wGA infants, which will be discussed in the next article. In 2018, the National Perinatal Association (NPA) raised concerns that excessive morbidity and increased hospitalization occurred as 


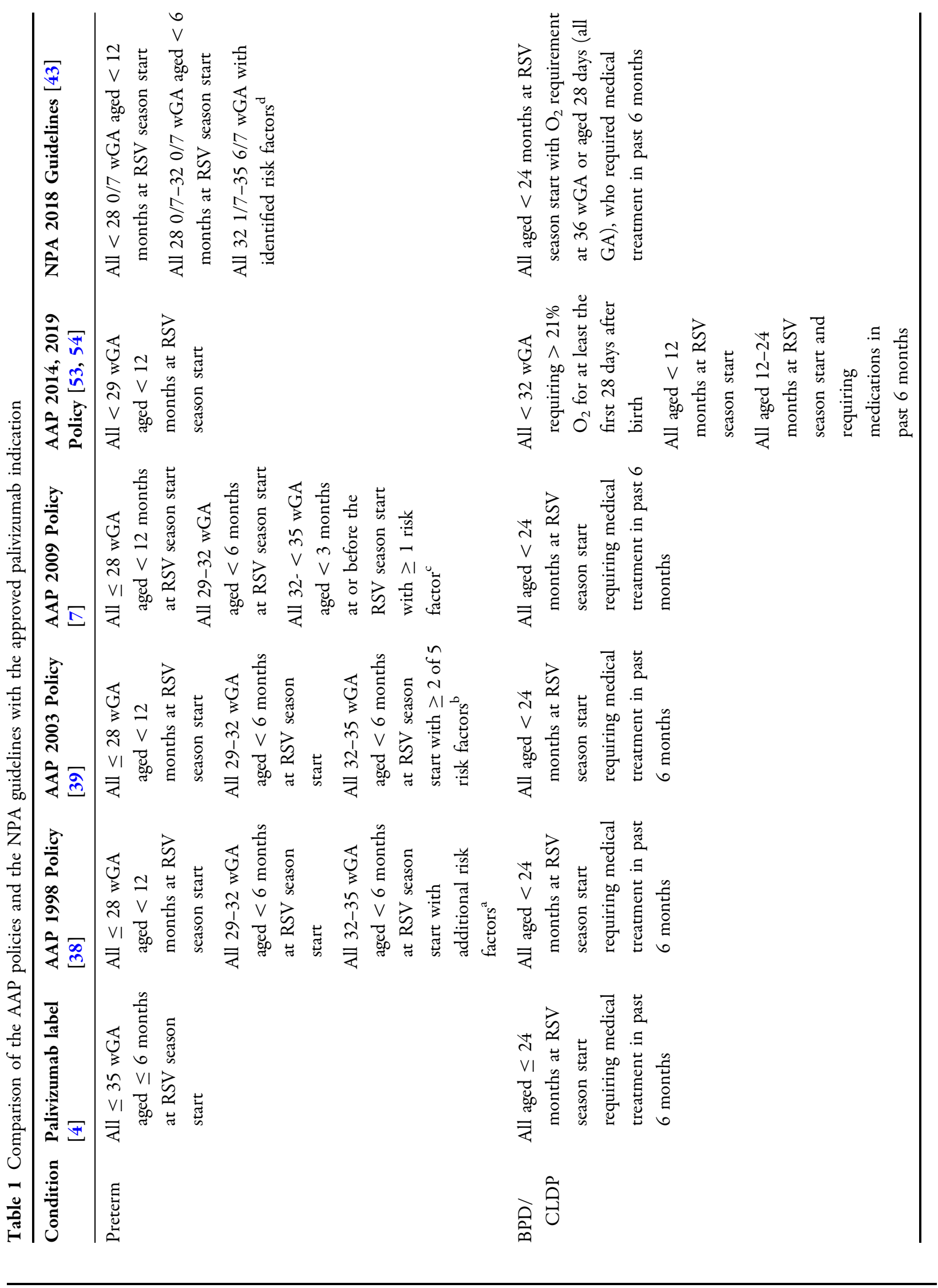




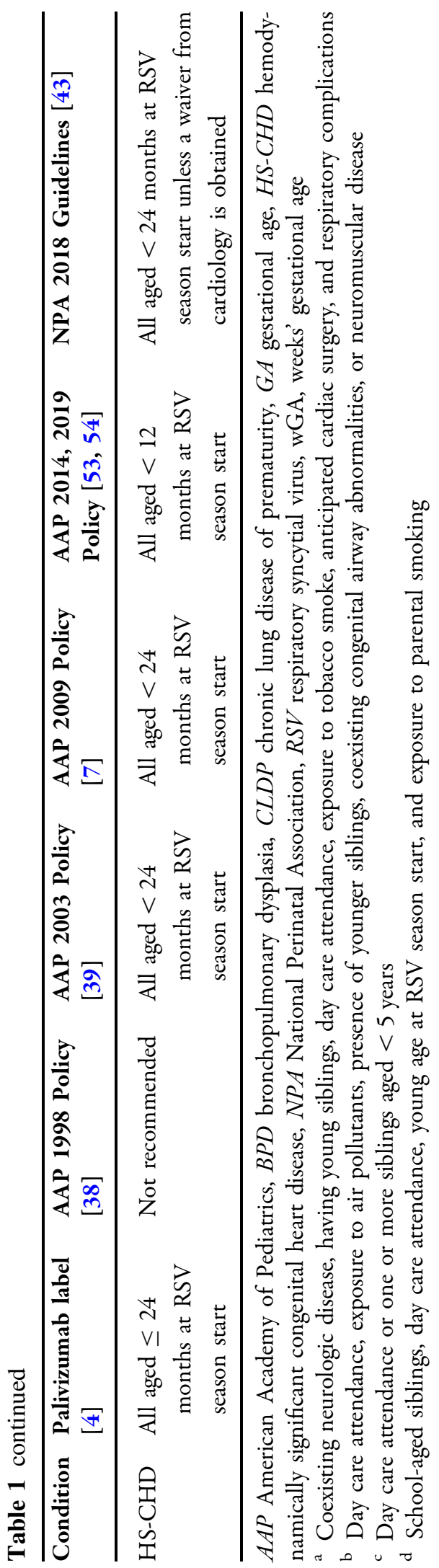

a result of providers and insurers following the more restrictive AAP policy. As such, the NPA published its own clinical practice guidelines and recommended RSV IP use for all children with BPD and CHD aged $<2$ years, all $\leq 32$ wGA infants, and 32-35 wGA infants with identified risk factors [43].

\section{RISK STRATIFICATION FOR THE PREVENTION OF RSV}

Targeted identification of populations at increased risk for severe RSV can help promote cost-effective use of RSV IP. Simple risk predictive tools can aid identification of high-risk moderate- to late-preterm infants (32-35 wGA infants) with high accuracy. In a pooled analysis of six large multicenter studies, Blanken et al. identified that birth around the RSV season, passive exposure to tobacco smoke, and day care attendance or presence of multiple younger siblings were significant risk factors for RSVH in 32-35 wGA infants $(P \leq 0.001)$ [58]. The large, observational SENTINEL1 study, including 46 centers across the US, reported that the major proportion of RSVH occurred soon after birth hospitalization discharge during the RSV season $(n=481)$. During the 2014-2016 RSV seasons studied (November to March), about half $(46 \%)$ and four-fifths $(82 \%)$ of $\mathrm{RSVH}$ occurred within 30 and 60 days, respectively, after birth hospitalization discharge [34]. Although the SENTINEL1 study only characterized the relationship between birth hospitalization and RSVH in preterm infants, the findings may be extended to young term infants as well. This is because both prematurity and younger chronologic age are independent risk factors for severe RSV $[59,60]$. Knowledge of risk predictive models and the association between birth hospitalization discharge and subsequent RSVH can be used to identify high-risk infants who may best benefit from RSV IP use.

\section{CONCLUSION}

Despite medical advances, RSV continues to be a burden on health care and society. Although 
the development of a vaccine for RSV has been a global priority, attempts to create a safe and effective vaccine have failed for more than 5 decades. Despite promising developments in this arena, a safe and effective RSV vaccine is still not imminent. As a result, palivizumab remains the only available immunotherapy to prevent severe RSV in high-risk infants, as it has been for the past 2 decades [41, 43]. Restricted recommendations by the AAP for RSV IP use in high-risk pediatric populations have largely led to an unfortunate increase in RSVH and morbidity. Based on this evidence, the NPA recommends RSV IP use for vulnerable 29-35 wGA infants and more closely aligns with the FDA indication for palivizumab. In light of the growing RSV burden, the AAP should revisit their policy for RSV IP in high-risk populations including $\geq 29$ wGA infants [43]. Risk stratification models can be used to help identify susceptible infants and children who would best benefit from RSV IP use [58].

\section{ACKNOWLEDGEMENTS}

This supplement has been sponsored by Sobi, Inc. Robert C. Welliver served as the Guest Editor for this supplement and has the following disclosures: He has received funding from Novavax for preclinical work on their RSV vaccine in a maternal immunization study, funding from $\mathrm{AZ}$ for evaluation of nirsevimab, past funding from AstraZeneca for various RSV antibody studies, and from MedImmune before that. He has also received funding from Regeneron in the past for their RSV monoclonal antibody study. Finally, he is receiving NIAID (1 R41 A147787-01) funding for study of an RSV vaccine.

Funding. This study and the Rapid Service Fees were sponsored by Sobi, Inc.

Medical Writing and Editorial Assistance. Writing and editorial support were provided by PRECISIONscientia, Inc., which were in accordance with Good Publication Practice (GPP3) guidelines and funded by Sobi, Inc.
Authorship. All named authors meet the International Committee of Medical Journal Editors (ICMJE) criteria for authorship for this article, take responsibility for the integrity of the work as a whole, and have given their approval for this version to be published.

Disclosures. Archana Chatterjee is a member of the AstraZeneca and Sobi Speakers Bureaus and was affiliated with Chicago Medical School and Rosalind Franklin University of Medicine and Science at the time of publication of this article. Kunjana Mavunda is a member of the Sobi Speakers Bureau. Leonard R. Krilov has received grant and research support for clinical trials from AstraZeneca, Regeneron, Pfizer, and Sanofi Pasteur. He has also been a consultant to Sobi as well as Pfizer.

Compliance with Ethics Guidelines. This article is based on previously conducted studies and does not contain any studies with human participants or animals performed by any of the authors.

Open Access. This article is licensed under a Creative Commons Attribution-NonCommercial 4.0 International License, which permits any non-commercial use, sharing, adaptation, distribution and reproduction in any medium or format, as long as you give appropriate credit to the original author(s) and the source, provide a link to the Creative Commons licence, and indicate if changes were made. The images or other third party material in this article are included in the article's Creative Commons licence, unless indicated otherwise in a credit line to the material. If material is not included in the article's Creative Commons licence and your intended use is not permitted by statutory regulation or exceeds the permitted use, you will need to obtain permission directly from the copyright holder. To view a copy of this licence, visit http://creativecommons.org/licenses/by$\mathrm{nc} / 4.0 /$. 


\section{REFERENCES}

1. Shi T, McAllister DA, O'Brien KL, Simoes EAF, Madhi SA, Gessner BD, et al. Global, regional, and national disease burden estimates of acute lower respiratory infections due to respiratory syncytial virus in young children in 2015: a systematic review and modelling study. Lancet (London, England). 2017;390(10098):946-58.

2. Blount RE Jr, Morris JA, Savage RE. Recovery of cytopathogenic agent from chimpanzees with coryza. Proc Soc Exp Biol Med. 1956;92(3):544-9.

3. Adams JM, Imagawa DT, Zike K. Epidemic Bronchiolitis and pneumonitis related to respiratory syncytial virus. JAMA. 1961;176(12):1037-9.

4. Afonso CL, Amarasinghe GK, Bányai K, Bào Y, Basler CF, Bavari S, et al. Taxonomy of the order Mononegavirales: update 2016. Adv Virol. 2016;161(8):2351-60.

5. Sullender WM, Britt WJ. Antigenic and immunogenic analysis of group A and group B respiratory syncytial virus $G$ proteins expressed from recombinant baculoviruses. J Gen Virol. 1996;77(Pt 4): 641-8.

6. Respiratory syncytial virus. In: Pickering LK, Baker CJ, Kimberlin DW, Long SS, editors. Red Book: 2003 Report of the Committee on Infectious Diseases. 26th ed. Elk Grove Village: American Academy of Pediatrics; 2003. pp 523-528.

7. Gilman MSA, Furmanova-Hollenstein P, Pascual G, van't Wout AB, Langedijk JPM, McLellan JS. Transient opening of trimeric prefusion RSV F proteins. Nat Commun. 2019;10(1):2105. https://doi.org/10. 1038/s41467-019-09807-5.

8. Fuentes S, Coyle EM, Beeler J, Golding H, Khurana S. Antigenic fingerprinting following primary RSV infection in young children identifies novel antigenic sites and reveals unlinked evolution of human antibody repertoires to fusion and attachment glycoproteins. PLoS Pathog. 2016;12(4): e1005554. https://doi.org/10.1371/journal.ppat. 1005554 .

9. Bont L, Versteegh J, Swelsen WT, Heijnen CJ, Kavelaars A, Brus F, et al. Natural reinfection with respiratory syncytial virus does not boost virusspecific T-cell immunity. Pediatr Res. 2002;52(3): 363-7.

10. Walsh EE, Falsey AR. Humoral and mucosal immunity in protection from natural respiratory syncytial virus infection in adults. J Infect Dis. 2004;190(2):373-8.
11. Glezen WP, Taber LH, Frank AL, Kasel JA. Risk of primary infection and reinfection with respiratory syncytial virus. Am J Dis Child. 1986;140(6):543-6.

12. Respiratory syncytial virus. In: Kimberlin DW, editor. Red Book: 2018 Report of the Committee on Infectious Diseases. 31st ed. Elk Grove Village: American Academy of Pediatrics; 2018. pp 682-692.

13. Wright M, Piedimonte G. Respiratory syncytial virus prevention and therapy: past, present, and future. Pediatr Pulmonol. 2011;46(4):324-47.

14. Hall CB. Respiratory syncytial virus: its transmission in the hospital environment. Yale J Biol Med. 1982;55(3-4):219-23.

15. Midgley CM, Haynes AK, Baumgardner JL, Chommanard C, Demas SW, Prill MM, et al. Determining the seasonality of respiratory syncytial virus in the United States: the impact of increased molecular testing. J Infect Dis. 2017;216(3):345-55. https:// doi.org/10.1093/infdis/jix275.

16. The National Respiratory and Enteric Virus Surveillance System (NREVSS). RSV census regional trends. https://www.cdc.gov/surveillance/nrevss/ rsv/region.html. Accessed 6 Sept 2019.

17. Rivera-Sepulveda A, Garcia-Rivera EJ. Epidemiology of bronchiolitis: a description of emergency department visits and hospitalizations in Puerto Rico, 2010-2014. Trop Med Health. 2017;45:24. https://doi.org/10.1186/s41182-017-0064-7.

18. Obando-Pacheco P, Justicia-Grande AJ, Rivero-Calle $\mathrm{I}$, Rodríguez-Tenreiro C, Sly P, Ramilo O, et al. Respiratory syncytial virus seasonality: a global overview. J Infect Dis. 2018;217(9):1356-64.

19. Leader S, Kohlhase K. Respiratory syncytial viruscoded pediatric hospitalizations, 1997 to 1999. Pediatr Infect Dis J. 2002;21(7):629-32.

20. Jain S, Williams DJ, Arnold SR, Ampofo K, Bramley $\mathrm{AM}$, Reed C, et al. Community-acquired pneumonia requiring hospitalization among U.S. children. N Engl J Med. 2015;372(9):835-45.

21. Zhou H, Thompson WW, Viboud CG, Ringholz CM, Cheng PY, Steiner C, et al. Hospitalizations associated with influenza and respiratory syncytial virus in the United States, 1993-2008. Clin Infect Dis. 2012;54(10):1427-36.

22. Collins PL, Crowe JE Jr. Respiratory syncytial virus and metapneumovirus. In: Knipe DM, Howley PM, Griffin DE, et al., editors. Fields' virology, vol. 2. 5th ed. Philadelphia: Lippincott Williams \& Wilkins; 2007. p. 1601-46. 
23. Ralston SL, Lieberthal AS, Meissner HC. Clinical practice guideline: the diagnosis, management, and prevention of bronchiolitis. Pediatrics. 2015;134(5): e1474-502.

24. Shi T, McAllister DA, O'Brien KL, Simoes EAF, Madhi SA, Gessner BD, et al. Global, regional, and national disease burden estimates of acute lower respiratory infections due to respiratory syncytial virus in young children in 2015: a systematic review and modelling study. Lancet. 2017;390(10098): 946-58.

25. Shi T, Denouel A, Tietjen AK, Campbell I, Moran E, $\mathrm{Li}$ X, et al. Global disease burden estimates of respiratory syncytial virus-associated acute respiratory infection in older adults in 2015: a systematic review and meta-analysis. J Infect Dis. 2019. https:// doi.org/10.1093/infdis/jiz059.

26. Haber N. Respiratory syncytial virus infection in elderly adults. Medecine et maladies infectieuses. 2018;48(6):377-82.

27. Griffiths C, Drews SJ, Marchant DJ. Respiratory syncytial virus: Infection, detection, and new options for prevention and treatment. Clin Microbiol Rev. 2017;30(1):277-319.

28. Tan CY, Chiu NC, Lee KS, Chi H, Huang FY, Huang DT, et al. Respiratory tract infections in children with tracheostomy. J Microbiol Immunol Infect. 2018. https://doi.org/10.1016/j.jmii.2018.07.002.

29. Manzoni P, Figueras-Aloy J, Simoes EAF, Checchia PA, Fauroux B, Bont L, et al. Defining the incidence and associated morbidity and mortality of severe respiratory syncytial virus infection among children with chronic diseases. Infect Dis Ther. 2017;6(3):383-411.

30. Bont L, Checchia PA, Fauroux B, Figueras-Aloy J, Manzoni P, Paes B, et al. Defining the epidemiology and burden of severe respiratory syncytial virus infection among infants and children in Western countries. Infect Dis Ther. 2016;5(3):271-98.

31. Checchia PA, Paes B, Bont L, Manzoni P, Simoes EA, Fauroux B, et al. Defining the risk and associated morbidity and mortality of severe respiratory syncytial virus infection among infants with congenital heart disease. Infect Dis Ther. 2017;6(1):37-56.

32. Figueras-Aloy J, Manzoni P, Paes B, Simoes EA, Bont L, Checchia PA, et al. Defining the risk and associated morbidity and mortality of severe respiratory syncytial virus infection among preterm infants without chronic lung disease or congenital heart disease. Infect Dis Ther. 2016;5(4):417-52.

33. Paes B, Fauroux B, Figueras-Aloy J, Bont L, Checchia PA, Simoes EA, et al. Defining the risk and associated morbidity and mortality of severe respiratory syncytial virus infection among infants with chronic lung disease. Infect Dis Ther. 2016;5(4): 453-71.

34. Anderson EJ, DeVincenzo JP, Simões EAF, Krilov LR, Forbes ML, Pannaraj PS, et al. SENTINEL1: twoseason study of respiratory syncytial virus hospitalizations among U.S. infants born at 29 to 35 weeks' gestational age not receiving immunoprophylaxis. Am J Perinatol. 2019. https://doi.org/10. 1055/s-0039-1681014.

35. Shi T, Arnott A, Semogas I, Falsey AR, Openshaw P, Wedzicha JA, et al. The etiological role of common respiratory viruses in acute respiratory infections in older adults: a systematic review and meta-analysis. J Infect Dis. 2019. https://doi.org/10.1093/infdis/ jiy662.

36. Cebey-López M, Herberg J, Pardo-Seco J, GómezCarballa A, Martinón-Torres N, Salas A, et al. Viral co-infections in pediatric patients hospitalized with lower tract acute respiratory infections. PLoS ONE. 2015;10(9):e0136526.

37. Calvo C, García-García ML, Pozo F, Paula G, Molinero $\mathrm{M}$, Calderón $\mathrm{A}$, et al. Respiratory syncytial virus coinfections with rhinovirus and human bocavirus in hospitalized children. Medicine (Baltimore). 2015;94(42):e1788.

38. Jung J, Seo E, Yoo RN, Sung H, Lee J. Clinical significance of viral-bacterial codetection among young children with respiratory tract infections: findings of RSV, influenza, adenoviral infections. Medicine (Baltimore). 2020;99(2):e18504.

39. Teo SM, Mok D, Pham K, Kusel M, Serralha M, Troy $\mathrm{N}$, et al. The infant nasopharyngeal microbiome impacts severity of lower respiratory infection and risk of asthma development. Cell Host Microbe. 2015;17(5):704-15.

40. Beigelman A, Isaacson-Schmid M, Sajol G, Baty J, Rodriguez OM, Leege E, et al. Randomized trial to evaluate azithromycin's effects on serum and upper airway IL-8 levels, and recurrent wheezing in infants with RSV bronchiolitis. J Allergy Clin Immunol. 2015;135(5):1171-8.

41. Simões EAF, Bont L, Manzoni P, Fauroux B, Paes B, Figueras-Aloy $\mathrm{J}$, et al. Past, present and future approaches to the prevention and treatment of respiratory syncytial virus infection in children. Infect Dis Ther. 2018;7(1):87-120.

42. Trang TP, Whalen M, Hilts-Horeczko A, Doernberg SB, Liu C. Comparative effectiveness of aerosolized versus oral ribavirin for the treatment of respiratory syncytial virus infections: a single-center retrospective cohort study and review of the literature. 
Transplant Infect Dis. 2018;20(2):e12844. https:// doi.org/10.1111/tid.

43. Goldstein M, Phillips R, DeVincenzo JP, Krilov LR, Merritt TA, Yogev R, et al. National Perinatal Association 2018 Respiratory Syncytial Virus (RSV) Prevention Clinical Practice Guideline: an evidence-based interdisciplinary collaboration. Neonatol Today. 2017;12(10):1-14.

44. Resch B. Product review on the monoclonal antibody palivizumab for prevention of respiratory syncytial virus infection. Hum Vaccine Immunother. 2017;13(9):2138-49.

45. Krilov LR, Masaquel AS, Weiner LB, Smith DM, Wade SW, Mahadevia PJ. Partial palivizumab prophylaxis and increased risk of hospitalization due to respiratory syncytial virus in a Medicaid population: a retrospective cohort analysis. BMC Pediatrics. 2014;14:261. https://doi.org/10.1186/14712431-14-261.

46. Shahabi A, Peneva D, Incerti D, McLaurin K, Stevens $W$. Assessing variation in the cost of palivizumab for respiratory syncytial virus prevention in preterm infants. PharmacoEconomics open. 2018;2(1):53-61.

47. The IMpact-RSV Study Group. Palivizumab, a humanized respiratory syncytial virus monoclonal antibody, reduces hospitalization from respiratory syncytial virus infection in high-risk infants. Pediatrics. 1998;102(3 Pt 1):531-7.

48. Feltes TF, Cabalka AK, Meissner HC, et al. Palivizumab prophylaxis reduces hospitalization due to respiratory syncytial virus in young children with hemodynamically significant congenital heart disease. J Pediatr. 2003;143(4):532-40.

49. Farber HJ, Buckwold FJ, Lachman B, Simpson JS, Buck E, Arun M, et al. Observed effectiveness of palivizumab for 29-36-week gestation infants. Pediatrics. 2016. https://doi.org/10.1542/peds. 2016-0627.

50. Anderson EJ, Carosone-Link P, Yogev R, Yi J, Simões EAF. Effectiveness of palivizumab in high-risk infants and children: a propensity score weighted regression analysis. Pediatr Infect Dis J. 2017;36(8): 699-704.

51. Bjornson C, Chan P, Li A, Paes B, Lanctôt KL, Mitchell I. Palivizumab prophylaxis for respiratory syncytial virus in infants with cystic fibrosis: is there a need? Europ J Clin Microbiol Infect Dis. 2018;37(6):1113-8.
52. Kua KP, Lee SWH. Systematic review of the safety and efficacy of palivizumab among infants and young children with cystic fibrosis. Pharmacotherapy. 2017;37(6):755-69.

53. American Academy of Pediatrics Committee on Infectious Diseases. American Academy of Pediatrics Bronchiolitis Guidelines Committee. Updated guidance for palivizumab prophylaxis among infants and young children at increased risk of hospitalization for respiratory syncytial virus infection. Pediatrics. 2014;134(2):415-20

54. American Academy of Pediatrics Committee on Infectious Diseases. American Academy of Pediatrics Bronchiolitis Guidelines Committee. Updated guidance for palivizumab prophylaxis among infants and young children at increased risk of hospitalization for respiratory syncytial virus infection. Pediatrics. 2014;134(2):415-20 (Reaffirmed February 2019).

55. Yogev R, Krilov LR, Fergie JE, Weiner LB. Re-evaluating the new committee on infectious diseases recommendations for palivizumab use in premature infants. Pediatr Infect Dis J. 2015;34(9):958-60.

56. Mac S, Sumner A, Duchesne-Belanger S, Stirling R, Tunis M, Sander B. Cost-effectiveness of palivizumab for respiratory syncytial virus: a systematic review. Pediatrics. 2019. https://doi.org/10.1542/ peds.2018-4064.

57. Blanken MO, Rovers MM, Molenaar JM, WinklerSeinstra PL, Meijer A, Kimpen JL, et al. Respiratory syncytial virus and recurrent wheeze in healthy preterm infants. N Engl J Med. 2013;368(19): 1791-9.

58. Blanken MO, Paes B, Anderson EJ, Lanari M, Sheridan-Pereira M, Buchan S, et al. Risk scoring tool to predict respiratory syncytial virus hospitalisation in premature infants. Pediatr Pulmonol. 2018;53(5):605-12.

59. Hall CB, Weinberg GA, Iwane MK, Blumkin AK, Edwards KM, Staat MA, et al. The burden of respiratory syncytial virus infection in young children. N Engl J Med. 2009;360(6):588-98.

60. Resch B, Puchas C, Resch E, Urlesberger B. Epidemiology of respiratory syncytial virus-related hospitalizations and the influence of viral coinfections in southern Austria in a 7-year period. Pediatr Infect Dis J. 2020;39(1):12-6. 